\title{
ISOLATION AND PARTIAL CHARACTERIZATION OF A MUTANT OF BACILLUS THURINGIENSIS PRODUCING MELANIN
}

\author{
Gislayne T. Vilas-Bôas ${ }^{1}$; Laurival A. Vilas-Bôas ${ }^{1}$; Veridiana T. Braz ${ }^{1}$; Halha O. Saridakis ${ }^{2}$; Clelton A. Santos ${ }^{1}$; \\ Olívia M. N. Arantes ${ }^{1 *}$
}

${ }^{1}$ Departamento de Biologia Geral, Centro de Ciências Biológicas, Universidade Estadual de Londrina, Londrina, PR, Brasil; ${ }^{2}$ Departamento de Microbiologia, Centro de Ciências Biológicas, Universidade Estadual de Londrina, Londrina, PR, Brasil

Submitted: March 08, 2005; Returned to authors for corrections: July 07, 2005; Approved: September 09, 2005

\section{SHORT COMMUNICATION}

\begin{abstract}
A mutant (407-P) of Bacillus thuringiensis subsp. thuringiensis strain 407 producing a melanin was obtained after treatment with the mutagenic agent ethyl-methane-sulfonate. Several microbiological and biochemical properties of the two strains were analyzed and the results were similar. The mutant 407-P was also incorporated into non-sterilized soil samples, recovered, easily identified, and quantified, what enables its use in ecology of B. thuringiensis.
\end{abstract}

Key-words: Bacillus thuringiensis, melanin, mutation, ecology

Bacillus thuringiensis is a spore-forming bacterium that produces highly specific insecticidal proteins, termed Cry proteins (7). Numerous Cry protein genes (called cry genes) have been classified into groups (http://epunix.biols.susx.ac.uk/ Home/Neil_Crickmore/Bt/). During sporulation, Cry proteins accumulate as crystalline inclusions within the cell. These crystals, when ingested by susceptible insects, are dissolved releasing monomers of the Cry proteins, followed by the proteolitic processing of the protoxin by midgut proteases, releasing the Cry toxin in its active form. The actived toxin binds to specific receptors on the apical brush border of the midgut microvillae of susceptible insects causing lysis of midgut epithelial cells and death of insect larvae (20).

Because of this mode of action with high specificity, microbial pesticides derived from $B$. thuringiensis present many advantages such as safety for non-target organisms, high specificity, low development of pest resistance and low environmental pollution. Therefore, $B$. thuringiensis-derived microbial pesticides are the most widely used in the world (4). However, the use of $B$. thuringiensis products is limited because the spores and toxins are highly sensitive to Ultra-violet (UV) radiation $(8,9,15)$ and because different formulations are inadequately stable under field conditions and rapidly lose their biological activities $(2,23)$.

Several investigators have reported that the production of melanin by various microorganisms protects their susceptibility to damage caused by UV and ionizing radiation $(1,16,17)$. Melanins are natural screens against both UV and visible light irradiation. They also provide additional protection against desiccation and attack by cell wall lytic enzymes (18).

Three methods have been utilized for obtaining $B$. thuringiensis products protected by pigments. I) Liu et al. (13) enhanced the UV resistance of $B$. thuringiensis by mixing $B$. thuringiensis with melanin produced by the fermentation of Streptomyces lividans 66 harboring a recombinant plasmid bearing the respective mel gene; II) Ruan et al. (17) constructed a recombinant $B$. thuringiensis strain expressing a novel mel gene under the control of the cry3 A gene expression system; III) Hoti and Balaraman (10) obtained a mutant of $B$. thuringiensis producing a dark-brown pigment, identified as melanin, by inducing mutagenesis.

*Corresponding Author. Mailing address: Departamento de Biologia Geral, CCB, UEL, Caixa Postal 6001. 86051-990, Londrina, PR, Brasil. Tel.: (+5543) 3371-4527. Fax: (+5543) 3328-4440. E-mail: oarantes@uel.br 
This study describes a method for obtaining a pigmentproducing mutant of $B$. thuringiensis subsp. thuringiensis 407 , utilizing ethylmethane-sulfonate (EMS). The nature of the pigment and the microbiological and biochemical characterization of the mutant supports its proposed application in the photoprotection of products derived from B. thuringiensis and in ecology studies as well.

B. thuringiensis subsp. thuringiensis 407 was mutagenized as described by Lecadet et al. (12) with some modifications. A suspension of spores $\left(3 \times 10^{8} \mathrm{~mL}^{-1}\right)$ in sterile distilled water was thereby used, and EMS was then added to give a concentration of $10 \% \mathrm{v} / \mathrm{v}$. The spores were incubated at $37^{\circ} \mathrm{C}$ for $40 \mathrm{~min}$. Afterward, the spores were washed twice with sterile water by centrifugation and ressuspended in $5 \mathrm{~mL}$ of sterile distilled water. Serial dilutions of the suspension were transferred onto Bacto Peptone BP (11) medium agar plates and incubated at $30^{\circ} \mathrm{C}$ for three days. The colonies formed were then selected based on pigment production. A mutant of B. thuringiensis subsp. thuringiensis 407 producing a dark-brown diffusible pigment was isolated after morphological screening of the colonies and designated B. thuringiensis subsp. thuringiensis 407-P (Fig. 1).

The strain 407 and the mutant 407-P were grown in different complex media: nutrient broth, Luria Bertoni broth (LB) and BP. Pigment production was determined in these media having $\mathrm{pH}$ adjusted to $4 ; 5 ; 6 ; 7 ; 8$, and 9 , either in broth cultures, with shaking at $200 \mathrm{rpm}$, or in agar plates at $30^{\circ} \mathrm{C}$, for three days. The mutant 407-P produced a dark-brown diffusible pigment both in nutrient broth, BP, and LB in liquid cultures and on agar plates. In liquid BP and LB media, pigment production started after $24 \mathrm{~h}$ and continued up to $48 \mathrm{~h}$. In nutrient broth, only weak

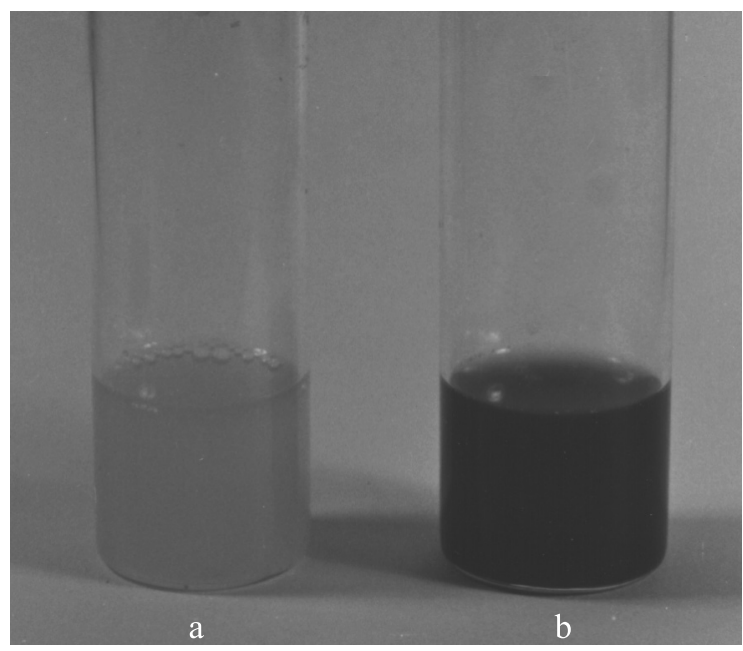

Figure 1. Bacillus thuringiensis subsp. thuringiensis 407 wild type strain (a) and the mutant 407-P producing pigment (b) in liquid LB medium. production of pigment was detected after $72 \mathrm{~h}$ of culture, which began only after $48 \mathrm{~h}$. Sporulation and crystal formation were monitored by phase-contrast microscopy, and were detected after $48 \mathrm{~h}$ in BP medium for both 407 and 407-P strains. For all media tested, the final $\mathrm{pH}$ of the cultures of the wild type strain was similar to the cultures of the 407-P mutant, and the optimum $\mathrm{pH}$ for pigment synthesis was 7. Similar results were shown in other studies $(9,10)$ that tested for pigment production in several media and under various conditions. The results demonstrated that various factors affect pigment production, such as bacterial growth rate, medium composition and availability of a specific substrate.

For pigment purification and identification, cultures of 407$\mathrm{P}$ strain were grown in LB medium at $30^{\circ} \mathrm{C}$ and $200 \mathrm{rpm}$ for $24 \mathrm{~h}$. Pigment was extracted from the supernatant based on the method described by Espinasse et al. (8). Pigment was precipitated by adding $1 \mathrm{M} \mathrm{HCl}$ to the supernatant, pelleted by centrifugation (10 min, $5000 \times g$ ), ethanol washed and dried. The extracted pigment was insoluble in hot and cold water, mineral acids, and solvents such as acetone and ethanol. It was completely solubilized by treatment with hot alkali $(5 \mathrm{M} \mathrm{KOH})$ solution and upon the addition of $0.1 \mathrm{M} \mathrm{FeCl}_{3}$, a flocculent brown precipitate was formed. A similar pigmented phenotype was previously described for two different $B$. thuringiensis subspecies exposed to mutagenic agents $(10,16,19)$.

The UV and visible absorption spectra of the pigment was obtained by spectrophotometer (Beckman DU640, Beckman, Coulter, Inc., Fullerton, CA, U.S.A.) scanning (Fig. 2) with the maximum absorbance at $205 \mathrm{~nm}$. Our results are similar to that of the melanin produced by other $B$. thuringiensis strains. Although different mutagenic agents have been used to induce the production of melanin, such as UV light $(16,19)$ and N-methylN'nitro-N-nitrosoguanidine (NTG) $(10,16,19)$. This is the first study that describes the utilization of EMS as the mutagenic agent to obtain melanin-producing mutants in B. thuringiensis.

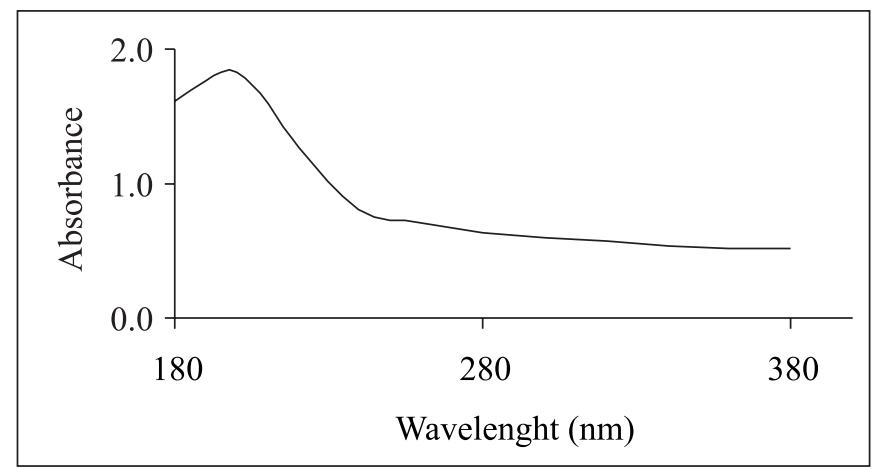

Figure 2. UV and visible spectra of the pigment from $B$. thuringiensis subsp. thuringiensis 407-P. 
For monitoring the multiplication of 407-P and wild-type strains growth curve were performed. A volume of $3 \%$ of a preculture 0.6 at $600 \mathrm{~nm}$ was added to $\mathrm{BP}$ medium at $30^{\circ} \mathrm{C}$ with shaking at $200 \mathrm{rpm}$ and incubated for $15 \mathrm{~h}$. Samples were taken each hour for optical density measurements and the setup of sporulation was monitored by phase-contrast microscopy. The results show that the growth curve of both 407-P and wild-type strains were identical with a reduced lag-phase and an increased $\log$ phase.

Susceptibility tests with commonly used antimicrobial agents were performed on LB agar by disk diffusion technique. The antibiotic disks (Cecon, São Paulo, Brazil) used were $10 \mu \mathrm{g}$ ampicillin, $30 \mu \mathrm{g}$ cefotaxime, $30 \mu \mathrm{g}$ ceftriaxone, $2 \mu \mathrm{g}$ clindamycin, $15 \mu \mathrm{g}$ erythromycin, $30 \mu \mathrm{g}$ kanamycin sulfate, $2 \mu \mathrm{g}$ lincomycin, $1 \mu \mathrm{g}$ oxacillin, IU penicillin $\mathrm{G} 10$ and $30 \mu \mathrm{g}$ vancomycin. Escherichia coli ATCC 25922 was used as control for bacterial growth and potency of antibiotics on disks. Inhibition disk zone sizes, interpreted according to the manufacturer's instructions, showed similar spectra for both mutant and the wild-type strains. Both were sensitive to clindamycin, erythromycin, kanamycin sulfate, vancomycin, and resistant to ampicillin, oxacillin, penicillin G, cefotaxime, ceftriaxone, and lincomycin.

Hemolytic activity was determined on sheep blood agar plates at $30^{\circ} \mathrm{C}(24)$. The hemolytic halos generated were analyzed and compared in intensity and in shape over time after $15 \mathrm{~h}$. The hemolytic activity of each strain (wild-type and mutant) was estimated twice and each replicate was classified as 'blind' with respect to the previous one. Gelatin-agar assays were performed for screening protease production in plates containing $1 \%(\mathrm{w} / \mathrm{v})$ gelatin and $1.5 \%(\mathrm{w} / \mathrm{v})$ agar. Spores were spotted on agar and, after three days of growth, the plate was flooded with $15 \%$ (w/ v) $\mathrm{HgCl}_{2}$ in $2 \mathrm{M} \mathrm{HCl}$. The unprecipitated clear zone showed the hydrolysis of gelatin due to the production of proteases. Protease production was measured as the ratio of the clear zone and of the colony diameters. These two tests were conducted to identify possible mutations in the pleiotropic activator PlcR, which regulates the production of extracellular proteins that are potentially involved in virulence, as phospholipases, proteases and hemolytic and non-hemolytic enterotoxins $(21,25)$. Both tests were positive for both strains, including the detection of hemolythic activity and the production of proteases. This result indicates that there was no alteration in the expression of this important regulon, which regulates the expression of more than 100 genes.

Wild type and the mutant strains were tested for several biochemical reactions: phenylalanine deaminase, nitrate reduction, glucose fermentation with production of acid and gas, mannitol fermentation, and amylase production $(3,14)$. Strains 407 and 407-P showed positive results for nitrate reduction, glucose fermentation with production of acid and gas and amylase production assays, and negative results for phenylalanine deaminase and mannitol fermentation assays.
These results indicate that there was no significant alteration in metabolic pathways responsibles for acquisition and consumption of organic and inorganic nutrients available in the environment.

In this study a melanin-producing mutant of $B$. thuringiensis (407-P) was evaluated with respect to the ability of growing in different complex media. Change in culture $\mathrm{pH}$, as well as sporulation and crystal production were monitored. In addition, susceptibility to several antimicrobial agents, the production of extracellular virulence factors (hemolysins and proteases) and the microbial properties of consumption and degradation of aminoacids and carbohydrates were also evaluated. No phenotypic alteration was detected in any of those traits. Therefore, it is suggested the utilization of the 407-P mutant to protect $B$. thuringiensis formulations from solar inactivation in the field, which appears to be one of the major environmental factors in the loss of their biological activity. Although various techniques have been reported to achieve the protection of $B$. thuringiensis formulations from solar inactivation $(2,5,6,22)$, melanin offers the advantage that it is a natural product that is easily biodegraded, thereby avoiding soil and water pollution.

The second application of the 407-P mutant is the study of the ecology of B. thuringiensis. In order to confirm this application, tests were conducted to potentially detect this mutant in non-sterilized environmental samples. Cells of the 407-P strain at exponential growth were suspended in $0.85 \%$ $\mathrm{NaCl}$ and incorporated into $35 \mathrm{~g}$ of soil in Petri dishes, to obtain $10^{8}$ cells $\mathrm{g}^{-1}$ of soil. The moisture content was kept at $80 \%$ of field capacity ( $33 \mathrm{~g}$ water per $100 \mathrm{~g}$ of dry soil) by adding sterile water, and the soil samples were incubated at $30^{\circ} \mathrm{C}$ for one week. In all experiments, non-sterilized soil samples were used without $\mathrm{pH}$ correction and with no nutrients addition. Spores were extracted after one, two and three days, by mixing $3.2 \mathrm{~g}$ of soil with $18.8 \mathrm{~mL}$ of saline and shaking for $10 \mathrm{~min}$ in a pendular shaker. After heat treatment $\left(70^{\circ} \mathrm{C}, 20 \mathrm{~min}\right)$, appropriate dilutions were plated on $\mathrm{BP}$ agar and incubated at $30^{\circ} \mathrm{C}$ for three days. The same treatment was made for soil samples without mutant cells addition. All the colonies obtained after heat treatment of the soil samples had Bacillus-like morphology. Pigmentproducing and non pigment-producing colonies were observed, making it possible to identify and quantify the presence of the strain introduced into the soil samples. No pigment producing colonies were observed in the control experiments.

This result shows that pigment-producing $B$. thuringiensis strains can be introduced into environmental such as sample soils, insects, and water and easily monitored, without antibiotics marker utilization. The ecology of $B$. thuringiensis depends largely on studies under environmental conditions. Therefore, pigment-producing strains can be an important tool for studying the ecology of $B$. thuringiensis, with respect to growth and survival, persistence of spores in the environment, and the ability of spores to spread to surrounding areas. 


\section{ACKNOWLEDGEMENTS}

This work was supported by grants from CNPq, CAPES and UEL. G.T.V.-B., L.A.V.-B. and C.A.S. were supported by fellowships from CNPq, CAPES and UEL. We also thank Dr. Albert Leyva for reading the manuscript.

\section{RESUMO}

\section{Isolamento e caracterização parcial de um mutante de Bacillus thuringiensis produtor de melanina}

Um mutante (407-P) da linhagem Bacillus thuringiensis subsp. thuringiensis 407 produtor de melanina foi obtido após tratamento com o agente mutagênico etil-metano-sulfonato. Diversas propriedades microbiológicas e bioquímicas das duas linhagens foram analisadas e os resultados foram similares. $\mathrm{O}$ mutante 407-P foi incorporado em amostras de solo não esterilizado, recuperado, facilmente identificado e quantificado, possibilitando seu uso em estudos de ecologia de $B$. thuringiensis.

Palavras-chave: Bacillus thuringiensis, melanina, mutação, ecologia

\section{REFERENCES}

1. Agodi, A.; Stefani, S.; Corsaro, C.; Campanile, F.; Gribaldo, S.; Sichel, G. Study of a melanic pigment of Proteus mirabilis. Res. Microbiol., 147, 167-174, 1996.

2. Blanco, M.G.M.; Wong, L.J.G.; Padilla, C.R.; Martinez, H.Q. Evaluation of polymer-based granular formulations of Bacillus thuringiensis israelensis against larval Aedes aegypti in the laboratory. J. Am. Mosq. Control Assoc., 18, 352-358, 2002.

3. Blazevic, D.J.; Ederer, G.M. Principles of biochemical tests in diagnostic microbiology (Techniques in pure and applied microbiology). John Wiley \& Sons, New York, 1975, 136 p.

4. Capalbo, D.M.F.; Vilas-Bôas, G.T.; Suzuki, M.T.; Arantes, O.M.N. Bacillus thuringiensis: formulações e plantas transgênicas. Biotecnolog. Cienc. Desenvolv., 34, 76-83, 2005.

5. Castro-Franco, R.; Garcia-Alvarado, J.S.; Galan-Wong, L.J. An alternative bioinsecticide formulation to encapsulate Bacillus thuringiensis delta toxin and extracts of Agave lecheguilla Torr. for the control of Spodoptera frugiperda Smith. Phyton-Int. J. Exp. Bot., 62, 71-77, 1998.

6. Cohen, E.; Joseph, T.; Wassermann-Golan, M. Photostabilization of biocontrol agents by berberine. Int. J. Pest Manage., 47, 63-67, 2001.

7. Crickmore, N.; Zeigler, D.R.; Feitelson, J.; Schnepf, E.; Van Rie, J.; Lereclus, D.; Baum, J.; Dean, D.H. Revision of the nomenclature for the Bacillus thuringiensis pesticidal crystal proteins. Microbiol. Mol. Biol. Rev., 62, 807-813, 1998.

8. Espinasse, S.; Gohar, M.; Lereclus, D.; Sanchis, V. An ABC transporter from Bacillus thuringiensis is essential for beta-exotoxin I production. J. Bacteriol., 184, 5848-5854, 2002.
9. Hinojosa-Rebollar, E.; Rangel-Mandujano, A.; Ortigoza-Ferado, J.; Mesta-Howard, A.Ma.; Hernández-Rodríguez, C. Synthesis and partial characterization of a melanin-like pigment of Bacillus subtilis. Rev. Lat.-Amer. Microbiol., 35, 399-406, 1993.

10. Hoti, S.L.; Balaraman, K. Formation of melanin pigment by a mutant of Bacillus thuringiensis H-14. J. Gen. Microbiol., 139, 2365-2369, 1993.

11. Lecadet, M.-M.; Blondel, M.O.; Ribier, J. Generalized transduction in Bacillus thuringiensis var. Berliner 1715, using bacteriophage CP54 Ber. J. Gen. Microbiol., 121, 203-212, 1980.

12. Lecadet, M.-M.; Klier, A.F.; Ribier, J. Isolation and characterization of two aspororgenous rifampicin resistant mutants of Bacillus thuringiensis. Biochimie, 56, 1471-1479, 1974.

13. Liu Y.T.; Sui M.J.; Ji D.D.; Wu I.H.; Chou C.C.; Chen C.C. Protection from ultraviolet irradiation by melanin of mosquitocidal activity of Bacillus thuringiensis var. israelensis. J. Invertebr. Pathol., 62, 131136, 1993.

14. Mac Faddin, J.F. Biochemical tests for identification of medical bacteria. 3rd ed. Williams \& Wilkins, Lippincott, 2000, 912 p.

15. Myasnik, M; Manasherob, R.; Ben-Dov, E.; Zaritsky, A.; Margalith, Y.; Barak, Z. Comparative sensitivity to UV-B radiation of two Bacillus thuringiensis subspecies and other Bacillus sp. Curr. Microbiol., 43, 140-143, 2001.

16. Patel, K.R.; Wyman, J.A.; Patel, K.A.; Burden, B.J. A mutant of Bacillus thuringiensis producing a dark-brown pigment with increased UV resistance and insecticidal activity. J. Invertebr. Pathol., 67, 120-124, 1996

17. Ruan, L.; Huang, Y.; Zhang, G.; Yu, D.; Ping, S. Expression of the mel gene from Pseudomonas maltophilia in Bacillus thuringiensis. Lett. Appl. Microbiol., 34, 244-248, 2002.

18. Ruan, L.F.; Yu, Z.N.; Fang, B.; He, W.; Wang, Y.J.; Shen, P. Melanin pigment formation and increased UV resistance in Bacillus thuringiensis following high temperature induction. Syst. Appl. Microbiol., 27, 286-289, 2004.

19. Saxena, D.; Ben-Dov, E.; Manasherob, R.; Barak, Z.; Boussiba, S.; Zaritsky, A. A UV tolerant mutant of Bacillus thuringiensis subsp. kurstaki producing melanin. Curr. Microbiol., 44, 25-30, 2002.

20. Schnepf, E.; Crickmore, N.; Van Rie, J.; Lereclus, D.; Baum, J.; Feitelson, J.; Zeigler, D.R.; Dean, D.H. Bacillus thuringiensis and it's pesticidal crystal proteins. Microbiol. Mol. Biol. Rev., 62, 775806, 1998.

21. Slamti, L.; Perchat, S.; Gominet, M.; Vilas-Bôas, G.; Fouet, A.; Mock, M.; Sanchis, V.; Chaufaux, J.; Gohar, M.; Lereclus, D. Distinct mutations in PlcR explain why some strains of Bacillus cereus group are non-hemolytic. J. Bacteriol., 186, 3531-3538, 2004.

22. Tamez-Guerra, P.; Mcguire, M.R.; Medranoroldan, H.; Galanwong, L.J.; Shasha, B.S.; Vega, F.E. Sprayable granule formulations for Bacillus thuringiensis. J. Econ. Entomol., 89, 1424-1430, 1996.

23. Toma, L.; Severini, F.; Bella, A.; Romi, R. A semifield evaluation of Vectobac (R) DT (ABG-6499), a new formulation of Bacillus thuringiensis israelensis for control of Aedes albopictus. J. Am. Mosq. Control Assoc., 19, 424-429, 2003.

24. Vilas-Bôas, G.T.; Sanchis, V.; Lereclus, D.; Lemos, M.V.F.; Bourguet, D. Genetic differentiation between sympatric populations of Bacillus cereus and Bacillus thuringiensis. Appl. Environ. Microbiol., 68, 1414-1424, 2002.

25. Vilas-Bôas, L.A.; Vilas-Bôas, G.F.L.T.; Saridakis, H.O.; Lemos, M.V.F.; Lereclus, D.; Arantes, O.M.N. Survival and conjugation of Bacillus thuringiensis in a soil microcosm. FEMS Microbiol. Ecol., 31, 255$259,2000$. 